\title{
Sufentanil Transdermal System
}

National Cancer Institute

\section{Source}

National Cancer Institute. Sufentanil Transdermal System. NCI Thesaurus. Code C84852.

A transdermal matrix patch formulation containing the synthetic opioid sufentanil with analgesic activity. Sufentanil binds to and activates the mu-opioid receptors in the central nervous system (CNS), thereby mimicking the effects of the endogenous opioids.

Binding of sufentanil to opioid receptors stimulates exchange of GTP for GDP, inhibits adenylate cyclase, and decreases intracellular cAMP. This inhibits the release of various nociceptive neurotransmitters, such as substance $P$, gamma-aminobutyric acid (GABA), dopamine, acetylcholine, noradrenaline, vasopressin, and somatostatin. In addition, sufentanil closes $\mathrm{N}$-type voltage-gated calcium channels and opens calcium-dependent inwardly rectifying potassium channels, which results in hyperpolarization of neuronal membranes and a reduction in neuronal excitability, and, subsequently, analgesia and sedation. 